\title{
Quality of work, economic crisis, and temporary employment
}

\author{
Xavier Bartoll \\ Agència de Salut Pública de Barcelona, Barcelona, Spain andlnstitut \\ d'Investigació Biomédica (IIB Sant Pau), Barcelona, Spain
}

Raul Ramos

Department of Econometrics, Statistics and Applied Economics, AQRIREA,Universitat de Barcelona, Barcelona, Spain

\begin{abstract}
Purpose: The objective of this paper is to analyse the impact of involuntary temporary versus permanent employment on the quality of work and its dimensions before and after the economic crisis in Spain.

Design/methodology/approach: Structural equations techniques are used to regress the type of contract on a measurement model for the quality of work and its dimensions as latent factors before and after the crisis. Data are drawn from the Quality of Working Life Surveys of 2006/07 and 2009/10.
\end{abstract}

Findings: The study's results show that in the two periods considered there are no differences in quality of work among male involuntary temporary workers and those with permanent contracts. However, there is an adverse widening gap across all dimensions of work for women in involuntary temporary employment during the economic crisis. There is a shift among men and women in involuntary temporary employment from valuing intrinsic job quality dimension in the pre-crisis period to valuing more the work environment one during the crisis period.

Research limitations: Our analysis is limited by the continuity of variables across years and the high proportion of missing values in some variables. The results cannot be interpreted in terms of causality due to additional consequences of the economic crisis.

Originality/value: This is the first study to consider whether deterioration in the Spanish labour market during the crisis affected the relationship between type of contract and dimensions of quality of work.

Keywords: Temporary employment, economic crisis, quality of work, structural equation model Article classification: Research paper 


\section{Introduction}

While becoming unemployed is considered to decrease an individual's well-being in the long run (Clark and Oswald, 1994), permanent and temporary workers who "survive" mass layoffs may also experience diminishing well-being due to the threat of the loss of employment (Vahtera \& Virtanen 2013) or of losing privileges achieved in times of economic growth when workers' bargaining positions were stronger. A high quality of work is important for workers well-being. It is positively correlated with life satisfaction (Bowling et al. 2010) and a diversity of physical and psychosocial health outcomes (see Barnay 2016 for a recent review). Temporary workers tent to be engaged in low quality jobs characterised by higher job insecurity compared to their permanent counterparts. As a consequence, they experience a higher prevalence of work-related stress and mental health problems (Virtanen et al. 2005). A working life with poor labour attachment may lead to social exclusion and even to a more stressful situation than remaining unemployed (Chandola and Zhang 2018).

The Spanish case is particularly interesting from this perspective. During the first years of the recent economic crisis, unemployment rates skyrocketed to $26.1 \%$ in 2013 from $8.2 \%$ in 2007 (INE 2016). Although firms' adjustments first affected temporary jobs, temporary employment levels remained relatively high by European standards, decreasing slowly from 33.2\% in 2006 to a $21.9 \%$ in 2013 , the lowest in the last two decades. Taking this into account, our objective is to analyse if the deterioration in the Spanish labour market during the crisis affected the self-assessed quality of jobs among permanent and involuntary temporary workers. Literature on the Spanish case is scarce. Only Borra and Gómez-Garcia (2016) illustrate the importance of the context of labour market downturns and high unemployment rates in relation to pre-crisis job satisfaction, but their analysis does not consider potential changes due to the recession. The literature that relates the quality of work and economic crisis has not considered the specific situation of temporary workers. This is a key issue in segmented labor markets such as Spain and that can offer results of interest from a comparative international perspective. In addition, the measurement of the quality of work has been applied a proven methodology that allows to assess the existing relationship between the variables considered for different dimensions, an aspect also little explored in the literature so far.

We also restrict our analysis to involuntary temporary employment, as it is a key factor influencing job quality (Kauhanen and Nätti, 2014). The of Working Lives Survey (ECVL as abbreviated in Spanish) data for 2006 to 2010 covers a wide range of working conditions and 
related labour arrangements. However, as few questions follow standard wordings required for sound psychometric instruments, the use of indicators alone is not recommended. Thus, we use a structural equation model (SEM) to construct latent factors representing different dimensions of job quality to gain validity and test if the constructs differ between temporary and permanent employment. The rest of the paper is organised into five sections. The next section provides a brief summary of the related literature. Section three describes the data and methods we use. Section four presents and discusses the results, and section five concludes.

\section{Literature review}

The concept of working life quality emerged in the 1940s from the field of psychology to address worker alienation. Early research highlights the difficulty of defining the multidimensional nature of working life quality, discussing the reciprocal effects of quality of life. Scholars studied how employees manage (or fail) to accommodate, compensate for, or transfer satisfaction with work to their quality of life. Martel and Dupuis (2006) offer a critical review of the ambiguity of defining job quality despite empirical advances.

The turning point occurred in 1997, when the European Employment Strategy and the Lisbon 2000 agenda aimed to boost labour market outcomes by not only creating employment, but by promoting quality and productivity at work as well.. The complexity lies in the multiple dimensions of jobs that should be taken into account, by the degree of objectivity or subjectivity of indicators, and the multiple levels on which jobs can be analysed, ranging from broad labour market systems in which jobs are performed and the particular work environment at the workplace level (Dahl et al., 2009; Leschke and Watt, 2013).

International organizations and academics (see Warhurst et al., 2017, for a review) have carried out a range of projects combining information at the individual and the macroeconomic levels. Problems with some of these macro-indices of quality of employment may be the redundancy of information across indicators or dimensions and methods of weighting and aggregation. Some degree of arbitrariness in weights and the proliferation of indicators and dimensions may hide the importance of relevant working conditions that, if not handled properly, can obscure their policy implications. More importantly, in a series of publications, Muñoz de Bustillo et al. (2011) complain that these job quality indexes include dimensions that are not strictly properties of workplace performance. 
In a more subjectivist framework, the quality of work is derived from the utility a worker derives from work. Job satisfaction is found to be a valid and reliable measure of subjective assessment of the overall and job dimensions (van Saane et al., 2003). Its main advantage is that it is the worker who judges his/her situation, although use of this indicator may be criticized as being influenced by contextual factors or as being adaptive over adverse working conditions. Within this literature, several authors have considered whether the type of contract influences workers' well-being (De Cuyper et al., 2008). Some studies find a significantly higher rate of job satisfaction among permanent workers over temporary workers (Benavides et al., 2000; Letourneux, 1998), probably due to the greater job insecurity of temporary workers (De Cuyper and De Witte, 2007). However, robust evidence of a lower job satisfaction has only been found for casual, seasonal, or agency workers (Bardasi and Francesconi, 2004).

From a theoretical perspective, and according to the demand-control and the effort-reward models, temporary workers are supposed to be vulnerable to poor working conditions. The demand-control model identifies job strain as the gap between the degree of control and autonomy over work and psychosocial demands (Karasek, 1979). The effort-reward imbalance model states that job strain comes from an imbalance between employee effort and perceived low compensation received for that effort, including salary (Siegrist, 1996). Workers can accept this situation if temporary employment can be justified as a stepping-stone to a permanent job. However, the empirical evidence on employment transitions shows the opposite (Booth et al., 2002; Güell and Petrongolo, 2007). Engagement in repeated temporary contracts in the early stages of one's working life lowers the probability of becoming a permanent employment in the years ahead (García-Pérez and Muñoz-Bullón, 2011; Sanz, 2011).

\section{Data and methods}

\section{Data and population}

Our sample is drawn from four surveys from 2006 to 2010 (the last edition) of the repeated cross-sectional study of ECVL. As the sample size per wave is relatively small, we pool surveys for 2006/07-before the crisis - and for 2009/10-after the economic crisis - to increase the number of observations and the reliability of our analysis. We discard data for 2008 , because this was the year when the economic crisis hit. The geographical scope of this survey is the 
entire national territory except for Ceuta and Melilla, although it is representative at the level of autonomous community (NUTS-2). The study population was restricted to salaried employees. We exclude, by design, those with voluntary temporary employment (726) and part-time contracts (in order to ease the interpretation of our results) $(4,181$ cases). With the objective of analysing a more homogeneous working population, we also exclude those below the age of 25 and above the age of 64 (1,023 and 71 cases, respectively) and foreign born (1,869 cases). We also exclude cases with missing values on some variables (2,804 cases), however weights were corrected accordingly. The final sample for the 2006/07 survey consists of 4,735 men and 2,920 women, and the 2009/10 survey consists of 4,864 men and 3,072 women.

\section{Variable definition}

The main explanatory variable in our analysis is the type of contract. The survey asks if the contract is permanent or temporary; if the contract is temporary, the survey asks if this contract condition is voluntary or involuntary. A dichotomous variable recodes permanent contracts as the base category with 0 and involuntary temporary as 1 .

We follow a subjectivist assessment of the quality of work, but combine elements of the demand-control and the effort-reward theories (Siegrist, 1996). Similar to Green and Mostafa (2010), we consider the first dimension as intrinsic job quality that captures satisfaction with work, personal development, and the autonomy of one's work, but we also include as a second dimension: satisfaction with earnings, training provided by the company, and satisfaction with the organization of the work in the company. A third dimension includes satisfaction with working time, including satisfaction with flexibility and rest time during the workday. This inclusion is meaningful in the context of the economic crisis, as working day arrangements are said to be among the channels that firms use to accommodate demand shocks. We have also extended the model to work environment dimension to capture relationships among colleagues and superiors, echoing the social support dimension (Johnson and Hall, 1988). Prior research has found that work environment serves as a buffer against adverse effects during the economic crisis (Díaz-Chao et al., 2014). The job prospects dimension measures the degree of commitment (participation in decisions), expectations (possibilities of promotion), and recognition from superiors. Job prospects was one of the early aspects occupational psychologists highlighted as important to perceived job satisfaction; the better the fit between expectations and job reality, the greater the worker's satisfaction, and 
vice versa (Locke, 1969). Finally, as the literature has shown that job insecurity is a key component of job (dis)satisfaction for temporary workers (Dawson et al., 2014) and our study relies on comparing the quality of work of temporary versus permanent employment, we include satisfaction with stability as an additional dimension. Individuals were asked for their degree of satisfaction for all items in a Likert scale from 0 'not at all satisfied' to 10 'very satisfied.'

Apart from the type of contract, personal traits may also affect individual evaluations of subjective work-related emotional states (Judge et al., 2002). Unfortunately, there is no information on personality in the surveys, so we use satisfaction with life as a proxy for personal traits, as a clear association has been established between job and life satisfaction (Hahn et al., 2013). Satisfaction with life is measured based on the same metrics of the 0 to 10 Likert scale.

Educational mismatch-the inadequacy between education level and skills required at the workplace-is another possible source influencing satisfaction with working conditions (Johnson and Johnson, 2000). For this reason, we added inadequacy as a covariate in four response items, from 'proper' to 'another kind of training is needed.'

Finally, socioeconomic covariates considered in the analysis include age (coded into four categories: 25-34; 35-44; 45-54; and 55-64), having children under age 15, having people who need care at home, marital status (with not living with a partner coded as 1 or 0 otherwise), maximum education level achieved (university degree as base category followed by secondary education and primary or less), firm size (more than 50 workers as 1 and less than 50 workers as 0), economic activity (nine categories according to the CNAE-93 one-digit classification), occupation (nine categories according to the CNO-94 one-digit classification), and dummies for each of the 17 regions (NUTS-2).

\section{Methods}

To assess differences in the overall quality of work and its dimensions of involuntary temporary vs permanent employment, we apply a structural equation model (SEM) (Brown, 2006) ${ }^{1}$. To specify the measurement model, we follow the analysis driven by theory previously

\footnotetext{
${ }^{1}$ Both models are estimated with the statistical software Stata 13 and LAVAAN package for R v3.4.2.
} 
cited and perform a principal components analysis to explore suggestive factors congruent with theory ${ }^{2}$. We report reliability measures with Cronbach's alpha. Each dimension represents a latent factor that is derived from observed indicator variables. Indicator variables are treated as continuous variables in the interval of $0-10$ points. Although indicator variables are close to the normal distribution in 0 kurtosis points and 3 of skewness, some variables exceed these limits of symmetry. This fact needs a correction, as non-normality in indicators represents a serious problem in small samples leading to poor fit (Hu and Bentler 1999). Although our sample may not be considered small, we relax the multivariate normality assumption by estimating multivariate likelihood with robust variance. To deal with the missing problem $(2,804$ cases $)$, we compute a variable taking value 1 if it is a missing value and 0 otherwise. We test the association between the missing variable and the main covariates with a Chi2 contrast. The significant associations found among some of these variables points to a missing at random (MAR) process. A predicted probability of non-missingness is obtained by applying a logistic regression on selected covariates. Computing an inverse probability on the predicted probabilities weights more individuals with a lower probability of inclusion in the final sample (Seaman and White, 2013). For a robustness check, we compute all results without applying inverse probability weight (IPW), obtaining the same results (data not shown).

Figure 1 summarizes our structural equation models for involuntary temporary vs. permanent employment for each dimension and overall quality of work. We compute two SEM model types. Model 1 estimates the effect of type of contract on each dimension separately. Model 2 carries out a similar analysis for the overall quality of work and for high discriminant dimensions only (factors with correlation values above 0.85 ). For this reason, model 2 only considers intrinsic job quality, working-time, and work environment.

Each model is estimated for the pre-crisis and crisis periods, 2006/07 and 2009/10 respectively. Comparing the measurement and the structural parts of the periods for each model enables an interpretation of the direction and strength of the changes in involuntary temporary employment versus permanent employment.

We report multiple goodness of fit statistics: standardized root mean square residuals (SRMR), the root mean square of the error approximation (RMSEA), comparative fit indices (CFI) and Tucker-Lewis index (TLI), Reference values for a good fit are RMSEA $<0.6$, SRMR $<0.8$, and CFI \&

\footnotetext{
${ }^{2}$ Results available from the authors on request.
} 
TLI>0.9 (Yu, 2002). Due to the simplicity of their settings and the good fit performance, we do not incorporate alternative models using modification indexes. All results are stratified by gender and period.

FIGURE 1

Due to the importance of insecurity as a determinant to working conditions for temporary workers, we include the stability dimension even though it is supported by only one indicator. We correct its variance by computing a conservative reliability value estimated by its correlation with overall job satisfaction (0.41). The error variance is computed as

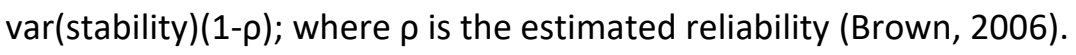

Standardized factor loadings are reported, which can be interpreted as correlations of the indicator and the factor. Squaring the factor loadings equals the amount of variance of the indicator explained by the factor; alternatively, the unique variance equals one minus this amount.

Of interest in the structural part of Model 1 is the coefficient of involuntary temporary employment for each quality of work dimension. In Model 2, of interest is the effect of involuntary temporary employment on the overall measure of quality of work. To ease the interpretation, we report unstandardized coefficients, that is, the amount of change in the quality of work dimension of moving from temporary to permanent employment, although we also report the coefficient as adjusted by the full set of covariates.

\section{Results and discussion}

Table 1 shows that $18.1 \%$ of men and $21.0 \%$ of women were involved in involuntary temporary employment in $2006 / 07$. These figures decrease slightly to $14.3 \%$ and $17.4 \%$ in $2009 / 10$. At base year, temporary employment is more common at young ages, from 25 to 34 , at $29.6 \%$ for men and a $30.1 \%$ for women, decreasing with age. Temporary employment is more common among those with a primary education ( $24 \%$ for men and $26.1 \%$ for women), among manual and non-qualified occupations (around one-third of these workers), in small firms for men (22.5\%) but without differences for women (20.5\%), in the construction sector for men $(41.1 \%)$ with a large decrease during the economic crisis to $16.5 \%$, and in the public services for 
women (23.8\%). Temporary employment decreases during the economic crisis in most categories for both sexes. See Table 1 for additional descriptive statistics.

TABLE 1

\section{Measurement model}

Reliability measures for each dimension in Table 2 show acceptable values for alpha Cronbach's around 0.75 except for rewards and prospects for 2009/10, and the values tend to be higher in 2006/07 than in 2009/10. Regarding Model 1 in Table 3, where temporary employment is related with each dimension separately, Table 3 shows that all standardised factor loadings are significant with few values below 0.7. Standardised factor loads can be interpreted as correlated with factor. For instance, the indicator activity developed correlates with the intrinsic job quality dimension at 0.72 for the $2006 / 07$ period, and this factor explains $52 \%\left(0.7238^{2}\right)$ of the variation of activity developed. It is possible to compare the contribution of each indicator to the factor across periods. The load of the personal development indicator becomes more relevant to the intrinsic job quality factor in the period 2009/10, with a value of 0.92 , than in the $2006 / 07$ period, with a value around 0.78 . The satisfactory estimation of each model is shown by the overall goodness of fit: all RMSEA are below or slightly exceed 0.06. All CFI are above 0.90 and all SRMR are far below 0.08 .

TABLES 2 and 3

Table 4 shows the standardised factor loadings of the second and first order hierarchical measurement Model 2. Second order measurement builds quality of work into three factor dimensions: intrinsic job quality, working time, and work environment. As mentioned, only highly discriminant dimensions are considered. Moreover, involuntary temporary employment, the structural part of the model, is highly correlated with the stability factor, which does not empirically guarantee identification. As in Model 1, the first order measurement relies on their respective indicators. The interpretation of the second order loadings is like those in Model 1. For instance, intrinsic job quality for men in the first period correlates with job quality at 0.98 , and job quality explains $0.97\left(0.98^{2}\right)$ of the variation in intrinsic job quality. It is worth noting that intrinsic job quality contributes to a higher degree to quality of work in period of $2006 / 07$ than in $2009 / 10$, while the inverse occurs for work environment, and working time remains stable across the period for both men and women. 
Model 2 fits the data well, as goodness of fit measured by the RMSEA are all close to 0.06 , the confidence interval is below 0.008 , the CFI are all above 0.95 , and the SRMR far below the recommended value of 0.08 .

TABLE 4

\section{Structural coefficients}

Table 5 shows the unstandardised regression coefficients of temporary employment on each five dimensions (Model 1) and on the overall quality of work index (Model 2, with only three dimensions: intrinsic job quality, working time, and work environment). The second half of the table shows adjusted coefficients to account for possible confounding effects of socioeconomics and firm characteristics.

\section{TABLE 5}

Regarding quality of work dimensions for men, temporary employment reduces satisfaction with stability by more than two points compared to permanent workers, which is the larger difference. During first period, men in temporary employment also experience lower satisfaction levels with intrinsic job quality (0.22), lower rewards (0.26), and lower prospects (0.39). Conversely, they are not less satisfied with working time. These figures decrease slightly after adjusting for individual and firm level covariates, but remain significant, except for work environment, where the positive difference loses significance. The lack of significance of the overall quality of work by type of contract in 2006/07 (having selected the three highly discriminant factors: intrinsic job quality, working time, and work environment) may be explained by negative satisfaction with intrinsic job quality, positive satisfaction with work environment, and neutral satisfaction with working time. When looking at 2009/10, the negative gap for permanent employment of intrinsic job dimensions vanishes, but the overall quality of work gap during the crisis period is not significant.

The picture for women in temporary employment compared to permanent employment is quite different. All dimensions in 2006/07 turn into negative gaps in 2009/10, and those that are already negative increase in magnitude, even in the adjusted solution. Larger negative differences are due to satisfaction with insecurity (above 3 points), reward (more than 0.6 points), prospects (more than 0.5 points), working time (around 0.4 points for adjusted and 
unadjusted solutions), intrinsic job quality (around 0.3 points), and work environment (above 0.15 points). Regarding the structural association between involuntary temporary employment versus permanent employment on the overall quality of work (on the selected factors), there is no significant difference across periods aside from a decreasing of quality of work (around 0.30 points) in 2009/10, either unadjusted or adjusted for a wide set of covariates. Thus, the economic crisis seems to have worsened the overall quality of work for women but not for men.

The main result of our analysis is an overall lack of significance for quality of work for men in involuntary temporary employment versus permanent employment for both periods, and the worsening of quality of work for women during the economic crisis. We highlight the importance of considering the dimensions of the quality of work, because it allows us to show the different weights given to each dimension before and during the economic crisis, and its possible trade off among dimensions and their differential evolution. For men, work environments improve and are more highly weighted during the economic crisis, while rewards, intrinsic job quality, and job prospects worsen. For women, most dimensions worsen more than for men.

The lack of overall significance of the quality of work for men in involuntary temporary employment may be related to the relevance of the unemployment of others and subjective welfare (Clark and Oswald, 1996). According to this line of argument, temporary workers who 'survive' layoffs are more at risk of dismissal than permanent workers, which directly worsens their well-being. That is, while peers' unemployment may contribute indirectly to a negative insecurity effect, it also has a positive comparison effect (Borra and Gómez-García, 2015). The 'others' unemployment' argument may partially explain why, in our measurement models, most indicators have reduced explanatory power during the economic crisis (except work environment that gain importance)-a sign that factors other than those included in quality of work matter. Job insecurity is confirmed as the main driver of the lower quality of work for temporary workers. As the literature highlights (Cheng and Chan, 2008; De Cuyper et al., 2008; Sverke et al., 2002), in the context of massive unemployment, fear of job loss increases even after adjustments. As expected, lower rewards, decreases in intrinsic job quality, and fewer job prospects are also confirmed for temporary employment compared to permanent employment, but for men the gap scarcely changes during the economic crisis and even shrinks for job prospects after adjustment. Our results show that employees put different weights on each dimension at peak and trough of the economic cycle. Intrinsic job quality 
contributes less and work environment contributes more in the overall assessment. The revalorisation of work environment was previously found for the overall working population (Díaz-Chao et al., 2014). Our results stress that the revalorisation effect is stronger among temporary employees. A reinforcement of internal cohesion or accommodation attitudes seems to be at play, especially in the relationship between directors and employees, as a response to the economic crisis. This behaviour has been labelled the "inhibitor effect"-i.e., when workers who fear job loss will do whatever they can to avoid it (Catalano et al., 2011).

Contrary to men, women in involuntary temporary employment experience significantly lower quality of work than those in permanent employment. Importantly, all negative associations in the pre-crisis period increase in magnitude, those not significant in pre-crisis period become negative during the economic crisis (intrinsic job quality and reward dimensions), as do those with positive associations in the pre-crisis period (working time and work environment dimensions). Although the argument that intrinsic job quality loses explanatory importance in favour of work environment, the 'others unemployment' argument also applies. The overwhelming worsening in all dimensions exceeds both explanations. The increase in dissatisfaction with working time points out that the supply of hours may dominate over both arguments. In our sample, the perceived need for overtime hours among women increased during the economic crisis, but not for men (data not shown). Getting a job or working more hours in a context of massive employment may imply harder work. An added-worker effect has been documented (Lundberg, 1985), which is much more significant for women whose labour supply increases by $21 \%$ when their partner is unemployed against a $0.7 \%$ increase experienced by men married to unemployed women. A relevant added-worker effect has also been detected for women if her partner works part-time. Larger labour supply variations are seen among those at the higher socioeconomic level (Addabbo et al., 2013). It has been reported that with declining incomes, the home production sector is a viable margin of substitution during business cycles (Aguiar et al., 2011). In Spain, there is evidence of declining household spending on items like catering, routine services of household maintenance, and outpatient services, so market working hours forgone due to the business cycle effect are reallocated to non-market production. This new economic context may lead adverse effects on work-life balance (Gash et al., 2012) besides job insecurity. Moreover, women take on additional responsibilities in terms of unpaid care work due to welfare cuts and privatisation (Buffel et al., 2015). 


\section{Conclusions}

Our objective was to analyse the impact of involuntary temporary versus permanent employment on quality of work before and after the economic crisis in Spain. We observe no differences by type of contract on the quality of work for men in both periods, but a decrease for women during the economic crisis and an adverse widening gap across all dimensions of quality of work. However, men in involuntary temporary employment experienced more insecurity, fewer rewards, and fewer prospects than workers in permanent positions across the periods studied. There is a shift among men in involuntary temporary employment from valuing intrinsic job quality in the pre-crisis period more the work environment during the crisis period; an 'inhibitor effect' appears to dominate. For women, this effect also holds, but we hypothesise that an 'added worker effect' for new entries (or longer hours) with harder working conditions and working-life balance may dominate over the 'inhibitor effect'.

Our paper has several strengths: it restricts its analysis to involuntary temporary employment, the model is theory-driven and built on a parsimonious measurement model with high overall performance, and it takes into account a wide range of potential confounding variables. In the absence of instruments with known properties, latent variables may be more robust, in terms or error measurement, than observable single item response. However, it also has some limitations. We have been limited by the continuity of variables across years and some dimensions. For instance, health and safety and physical environment were discarded due to the high proportion of missing values. Compositional effects of workforces across the periods studied cannot be ruled out, and the results cannot be interpreted in terms of causality due to additional consequences of the economic crisis. Nonetheless, we have partially minimized this drawback by adjusting each period for a wide set of covariates. A selection process by which 'survivor' temporary employees are presumably already more engaged with firm goals may be at play - a fact that would run against finding differences during the economic crisis period, when, in fact, we do find differences. In this sense, the adverse effects found during the economic crisis are prudent results as the excluded sub-groups population from the analysis, foreign born workers, and part-time employment (especially for women) are usually engaged in low quality jobs, so that their inclusion could make the results worse when inferred to all employee, a fact that has to be cautious regarding the external validity of the results. More generally, skewed distributions in some items and the assumed multivariate normality in SEM may lead to wrong estimations; however large samples, as in our case, tent to reduce this 
problem. Another hypothesis is that conditioned to the latent factor the covariance between the items that built this latent factor should be not significant, otherwise the estimation would be unstable. We look at the reproduced residual variance-covariance matrix to check this assumption and confirm that the correlation among items is enough reproduced by the model. The inclusion of further constraints (additional paths, factor covariances, and indicator error covariances) may improve the goodness of fit but limit the external validity of the final model.

The extent to which the worse working conditions observed among temporary employees might extend to permanent employees remains an important research question. As labour legislation is more stringent for permanent than temporary employees, attempts to gain flexibility by promoting a Single/Unified Open-Ended Contract (SOEC) for new hires, consistent on a severance pay schedule and increasing with tenure for all types of employment, may have an adverse effect on the job security of permanent employees.

\section{Acknowledgments:}

The usual disclaimer applies. Raul Ramos gratefully acknowledges the support received from the Spanish Ministry of Economy and Competitiveness through the project ECO2016-75805-R. The authors are also grateful to the comments received from the editor and the anonymous referees during the evaluation process.

\section{Conflict of interest:}

No competing interest 


\section{References}

Addabbo, T., Rodríguez-modroño, P. \& Gálvez-muñoz, L., 2013. Gender and the Great Recession: Changes in labour supply in Spain. Economic Systems, 39, pp.27-42.

Aguiar, M.A., Hurst, E. \& Karabarbounis, L., 2011. Time use during recessions, Available at: http://www.nber.org/papers/w17259.pdf.

Bardasi, E. \& Francesconi, M., 2004. The impact of atypical employment on individual wellbeing: Evidence from a panel of British workers. Social Science and Medicine, 58(9), pp.1671-1688.

Barnay, T., 2016. Health, work and working conditions : a review of the European economic literature. The European Journal of Health Economics, 17(6), pp.693-709. Available at: "http://dx.doi.org/10.1007/s10198-015-0715-8.

Benavides, F.G. et al., 2000. How do types of employment relate to health indicators? Findings from the Second European Survey on Working Conditions. Journal of Epidemiology and Community Health, 54, pp.494-501.

Booth, A.L., Francesconi, M. \& Frank, J., 2002. Temporary jobs: Stepping stones or dead ends? Economic Journal, 112.

Borra, C. \& Gómez-García, F., 2015. Wellbeing at Work and the Great Recession: The Effect of Others' Unemployment. Journal of Happiness Studies, 17(5), pp.1939-1962. Available at: http://link.springer.com/10.1007/s10902-015-9679-8 [Accessed January 24, 2017].

Bowling, N.A., Eschleman, K.J. \& Wang, Q., 2010. A meta-analytic examination of the relationship between job satisfaction and subjective well-being. Journal of Occupational and Organizational Psychology, 83, pp.915-934.

Brown, T.A., 2006. Confirmatory Factor Analysis for Applied Research, Guilford Press.

Buffel, V., Van de Velde, S. \& Bracke, P., 2015. The mental health consequences of the economic crisis in Europe among the employed, the unemployed, and the non-employed. Social Science Research, 54, pp.263-288.

Catalano, R. et al., 2011. The Health Effects of Economic Decline. Annual Review of Public Health, 32, pp.431-450. Available at:

http://www.annualreviews.org/doi/10.1146/annurev-publhealth-031210-101146.

Chandola, T. \& Zhang, N., 2018. Re-employment, job quality, health and allostatic load biomarkers: Prospective evidence from the UK Household Longitudinal Study. International Journal of Epidemiology, 47, pp.47-57.

Cheng, G.H.L. \& Chan, D.K.S., 2008. Who suffers more from job insecurity? A meta-analytic review. Applied Psychology, 57, pp.272-303.

Clark, A.E. \& Oswald, A.J., 1996. Satisfaction and comparison income. Journal of Public Economics, 61, pp.359-381. 
Clark, A.E. \& Oswald, A.J., 1994. Unhappiness and Unemployment. Economic Journal, 104, pp.648-659. Available at:

http://search.ebscohost.com/login.aspx?direct=true\&db=buh\&AN=9411075483\&site=eh ost-live.

De Cuyper, N. et al., 2008. Literature review of theory and research on the psychological impact of temporary employment: Towards a conceptual model. International Journal of Management Reviews, 10, pp.25-51.

De Cuyper, N. \& De Witte, H., 2007. Job insecurity in temporary versus permanent workers: Associations with attitudes, well-being, and behaviour. Work and Stress, 21, pp.65-84.

Dahl, S., Nesheim, T. \& Olsen, K., 2009. Quality of work: concept and measurement, Edimburg.

Dawson, C., Veliziotis, M. \& Hopkins, B., 2014. Temporary employment, job satisfaction and subjective well-being. Economic and Industrial Democracy, Advance On, pp.1-30. Available at: http://eid.sagepub.com/cgi/doi/10.1177/0143831X14559781.

Díaz-Chao, A., Ficapal-Cusí, P. \& Torrent-Sellens, J., 2014. Workplace or working environment? Job quality and economic crisis in Spain, EconStor Preprints 162057, ZBW - German National Library of Economics.

García-Pérez, J.I. \& Muñoz-Bullón, F., 2011. Transitions into Permanent Employment in Spain: An Empirical Analysis for Young Workers. British Journal of Industrial Relations, 49, pp.103-143.

Gash, V., Mertens, A. \& Gordo, L.R., 2012. The Influence Of Changing Hours Of Work On Women's Life Satisfaction. Manchester School, 80(1), pp.51-74.

Green, F. \& Mostafa, T., 2010. JOB QUALITY INDICES FOR EUROPE. A Report Based On The Fifth European Working Conditions Survey, London.

Güell, M. \& Petrongolo, B., 2007. How binding are legal limits? Transitions from temporary to permanent work in Spain. Labour Economics, 14, pp.153-183.

Hahn, E., Johnson, W. \& Spinath, F.M., 2013. Beyond the heritability of life satisfaction - The roles of personality and twin-specific influences. Journal of Research in Personality, 47, pp.757-767.

Hu, L.T. \& Bentler, P.M., 1999. Cutoff criteria for fit indexes in covariance structure analysis: Conventional criteria versus new alternatives. Structural Equation Modeling, 6, pp.1-55.

INE, 2016. EAPS. Economically Active Population Survey. Available at: http://www.ine.es/dynt3/inebase/es/index.htm?padre=811\&capsel=815 [Accessed November 20, 2016].

Johnson, G.J. \& Johnson, W.R., 2000. Perceived overqualification and dimensions of job satisfaction: A longitudinal analysis. Journal of Psychology: Interdisciplinary and Applied, 134, pp.537-555. 
Johnson, J. V \& Hall, E.M., 1988. Job strain, work place social support, and cardiovascular disease: a cross-sectional study of a random sample of the Swedish working population. American journal of public health, 78, pp.1336-42. Available at: http://www.pubmedcentral.nih.gov/articlerender.fcgi?artid=1349434\&tool=pmcentrez\& rendertype=abstract.

Judge, T.A., Heller, D. \& Mount, M.K., 2002. Five-factor model of personality and job satisfaction: A meta-analysis. Journal of Applied Psychology, 87, pp.530-541.

Karasek, R.A., 1979. Job Demands, Job Decision Latitude, and Mental Strain: Implications for Job Redesign. Administrative Science Quarterly, 24(2), pp.285-308.

Kauhanen, M. \& Nätti, J., 2014. Involuntary Temporary and Part-Time Work, Job Quality and Well-Being at Work. Social Indicators Research, pp.783-799.

Leschke, J. \& Watt, A., 2013. Challenges in constructing a multi-dimensional European job quality index. Social Indicators Research, 118, pp.1-31.

Letourneux, V., 1998. Precarious Employment and Working Conditions in Europe, Luxembourg.

Locke, E.A., 1969. What is job satisfaction? Organizational Behavior and Human Performance, 4, pp.309-336. Available at: http://linkinghub.elsevier.com/retrieve/pii/0030507369900130.

Lundberg, S., 1985. The Added Worker Effect. Journal of Labor Economics, 3, p.11.

Martel, J.-P. \& Dupuis, G., 2006. Quality of Work Life: Theoretical and Methodological Problems, and Presentation of a New Model and Measuring Instrument. Social Indicators Research, 77(2), pp.333-368.

Muñoz de Bustillo, R. et al., 2011. Measuring more than money: the social economics of job quality., Cheltenham: Edward Elgar.

Van Saane, N. et al., 2003. Reliability and validity of instruments measuring job satisfaction--a systematic review. Occupational Medicine, 53, pp.191-200.

Sanz, Y.R., 2011. Landing a permanent contract in spain: Do job interruptions and employer diversification matter? Manchester School, 79, pp.1197-1236.

Seaman, S.R. \& White, I.R., 2013. Review of inverse probability weighting for dealing with missing data. Statistical Methods in Medical Research, 22, pp.278-295.

Siegrist, J., 1996. Adverse Health Effects of High-Effort/Low-Reward Conditions. Journal of Occupational Health Psychology House Karasek \& Theorell La Ferla \& Levi, 1(1), pp.27-41.

Sverke, M., Hellgren, J. \& Näswall, K., 2002. No security: a meta-analysis and review of job insecurity and its consequences. Journal of occupational health psychology, 7, pp.242264.

Vahtera, J. \& Virtanen, M., 2013. The health effects of major organisational changes. Occupational and Environmental Medicine, 70, pp.677-678. 
Virtanen, M. et al., 2005. Temporary employment and health: A review. International Journal of Epidemiology, 34(3), pp.610-622.

Warhurst, C., Wright, S. \& Lyonette, C., 2017. Understanding and measuring job quality, Research report. Warwick Institute for Employment Research.

Yu, C.Y., 2002. Evaluating cutoff criteria of model fit indices for latent variable models with binary and continous outcomes. Available at:

http://statmodel2.com/download/Yudissertation.pdf. 
Table 1. Distribution of the sample of involuntary temporary employment by gender and period.

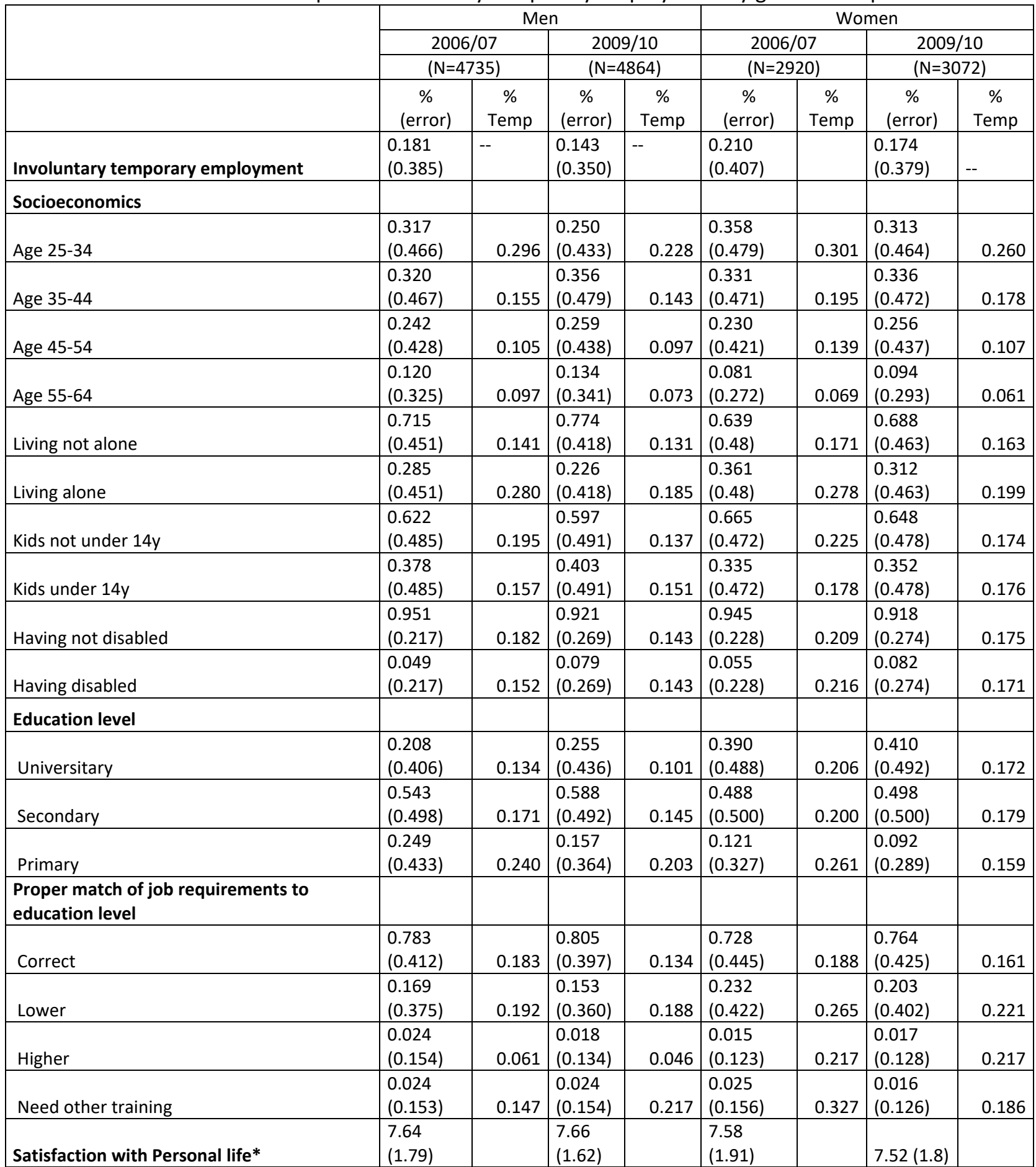




\begin{tabular}{|c|c|c|c|c|c|c|c|c|}
\hline \multicolumn{9}{|l|}{ Occupation } \\
\hline $\begin{array}{l}\text { Management of companied and public } \\
\text { administration }\end{array}$ & $\begin{array}{ll}0.040 \\
(0.196)\end{array}$ & 0.039 & $\begin{array}{l}0.045 \\
(0.208)\end{array}$ & 0.039 & $\begin{array}{l}0.026 \\
(0.160) \\
\end{array}$ & 0.054 & $\begin{array}{l}0.037 \\
(0.188) \\
\end{array}$ & 0.060 \\
\hline $\begin{array}{l}\text { Technicians scientific professionals and } \\
\text { intellectual }\end{array}$ & $\begin{array}{l}0.122 \\
(0.327)\end{array}$ & 0.124 & \begin{tabular}{|l|}
0.145 \\
$(0.352)$
\end{tabular} & 0.122 & \begin{tabular}{|l|}
0.236 \\
$(0.425)$
\end{tabular} & 0.190 & \begin{tabular}{|l|}
0.228 \\
$(0.420)$
\end{tabular} & 0.199 \\
\hline Technicians and support professionals & $\begin{array}{ll}0.152 \\
(0.359)\end{array}$ & 0.128 & $\begin{array}{l}0.175 \\
(0.380)\end{array}$ & 0.105 & \begin{tabular}{|l|}
0.206 \\
$(0.405)$
\end{tabular} & 0.147 & $\begin{array}{l}0.253 \\
(0.435)\end{array}$ & 0.119 \\
\hline Employees of administrative type & $\begin{array}{l}0.067 \\
(0.250)\end{array}$ & 0.095 & \begin{tabular}{|l|}
0.051 \\
$(0.221)$ \\
\end{tabular} & 0.114 & \begin{tabular}{|l|}
0.154 \\
$(0.361)$
\end{tabular} & 0.212 & \begin{tabular}{|l|}
0.126 \\
$(0.331)$
\end{tabular} & 0.217 \\
\hline $\begin{array}{l}\text { Workers of catering services, personal, } \\
\text { protection and sellers of shops }\end{array}$ & $\begin{array}{l}0.096 \\
(0.295)\end{array}$ & 0.109 & \begin{tabular}{|l|}
0.114 \\
$(0.318)$
\end{tabular} & 0.124 & \begin{tabular}{|l|}
0.189 \\
$(0.391)$
\end{tabular} & 0.210 & \begin{tabular}{|l|}
0.207 \\
$(0.405)$
\end{tabular} & 0.164 \\
\hline Skilled workers in agriculture and fishing & $\begin{array}{l}0.015 \\
(0.123)\end{array}$ & 0.156 & \begin{tabular}{|l|}
0.018 \\
$(0.133)$ \\
\end{tabular} & 0.200 & \begin{tabular}{|l|}
0.004 \\
$(0.066)$
\end{tabular} & 0.618 & \begin{tabular}{|l|}
0.003 \\
$(0.059)$ \\
\end{tabular} & 0.339 \\
\hline $\begin{array}{l}\text { Craftsmen and skilled workers from } \\
\text { manufacturing, construction, and mining }\end{array}$ & \begin{tabular}{|l|l|}
0.248 \\
$(0.432)$
\end{tabular} & 0.285 & $\begin{array}{l}0.217 \\
(0.412) \\
\end{array}$ & 0.193 & \begin{tabular}{|l|}
0.042 \\
$(0.201)$ \\
\end{tabular} & 0.251 & $\begin{array}{l}0.030 \\
(0.170) \\
\end{array}$ & 0.204 \\
\hline $\begin{array}{l}\text { Operators of facilities and machinery, and } \\
\text { assemblers }\end{array}$ & $\begin{array}{l}0.161 \\
(0.368)\end{array}$ & 0.162 & \begin{tabular}{|l|}
0.149 \\
$(0.356)$ \\
\end{tabular} & 0.125 & \begin{tabular}{|l|}
0.035 \\
$(0.183)$ \\
\end{tabular} & 0.319 & \begin{tabular}{|l|}
0.027 \\
$(0.163)$ \\
\end{tabular} & 0.194 \\
\hline Non-qualified workers & $\begin{array}{l}0.098 \\
(0.297)\end{array}$ & 0.290 & \begin{tabular}{|l|}
0.085 \\
$(0.279)$
\end{tabular} & 0.249 & \begin{tabular}{|l|}
0.107 \\
$(0.309)$
\end{tabular} & 0.340 & $\begin{array}{l}0.089 \\
(0.285) \\
\end{array}$ & 0.281 \\
\hline \multicolumn{9}{|l|}{ Number of workers } \\
\hline Less or 50 & \begin{tabular}{|l|l|}
0.406 \\
$(0.491)$
\end{tabular} & 0.225 & $\begin{array}{l}0.383 \\
(0.486)\end{array}$ & 0.187 & \begin{tabular}{|l|}
0.339 \\
$(0.474)$
\end{tabular} & 0.205 & \begin{tabular}{|l|}
0.327 \\
$(0.469)$
\end{tabular} & 0.171 \\
\hline More than 50 & $\begin{array}{ll}0.594 \\
(0.491) \\
\end{array}$ & 0.150 & \begin{tabular}{|l|}
0.617 \\
$(0.486)$ \\
\end{tabular} & 0.116 & \begin{tabular}{|l|}
0.661 \\
$(0.474)$ \\
\end{tabular} & 0.212 & \begin{tabular}{|l|}
0.673 \\
$(0.469)$ \\
\end{tabular} & 0.176 \\
\hline \multicolumn{9}{|l|}{ Economic activity } \\
\hline Agriculture \& Extractive industries & $\begin{array}{ll}0.083 \\
(0.277)\end{array}$ & 0.209 & $\begin{array}{l}0.092 \\
(0.289)\end{array}$ & 0.221 & \begin{tabular}{|l|}
0.081 \\
$(0.272)$
\end{tabular} & 0.296 & \begin{tabular}{|l|}
0.063 \\
$(0.242)$
\end{tabular} & 0.175 \\
\hline Machinery & $\begin{array}{l}0.133 \\
(0.340)\end{array}$ & 0.143 & \begin{tabular}{|l|}
0.133 \\
$(0.34)$
\end{tabular} & 0.095 & \begin{tabular}{|l|}
0.057 \\
$(0.233)$
\end{tabular} & 0.148 & \begin{tabular}{|l|l|}
0.045 \\
$(0.207)$
\end{tabular} & 0.099 \\
\hline Light industry \& reparations & $\begin{array}{l}0.055 \\
(0.228)\end{array}$ & 0.156 & \begin{tabular}{|l|}
0.043 \\
$(0.203)$
\end{tabular} & 0.170 & $\begin{array}{l}0.029 \\
(0.167)\end{array}$ & 0.207 & $\begin{array}{l}0.015 \\
(0.12)\end{array}$ & 0.036 \\
\hline Construction \& wholesale trade & $\begin{array}{l}0.179 \\
(0.383)\end{array}$ & 0.411 & \begin{tabular}{|l|}
0.277 \\
$(0.448)$
\end{tabular} & 0.165 & \begin{tabular}{|l|}
0.027 \\
$(0.163)$ \\
\end{tabular} & 0.309 & \begin{tabular}{|l|}
0.156 \\
$(0.363)$ \\
\end{tabular} & 0.146 \\
\hline Transportation \& editorial services & $\begin{array}{l}0.157 \\
(0.364)\end{array}$ & 0.121 & \begin{tabular}{|l|}
0.075 \\
$(0.263)$ \\
\end{tabular} & 0.158 & \begin{tabular}{|l|}
0.182 \\
$(0.386)$ \\
\end{tabular} & 0.209 & \begin{tabular}{|l|}
0.079 \\
$(0.270)$ \\
\end{tabular} & 0.190 \\
\hline Financial and insurance services & \begin{tabular}{|l|}
0.119 \\
$(0.324)$
\end{tabular} & 0.091 & \begin{tabular}{|l|}
0.082 \\
$(0.274)$ \\
\end{tabular} & 0.056 & \begin{tabular}{|l|}
0.075 \\
$(0.264)$
\end{tabular} & 0.166 & \begin{tabular}{|l|}
0.106 \\
$(0.308)$
\end{tabular} & 0.114 \\
\hline Advanced services & \begin{tabular}{|l|}
0.185 \\
$(0.389)$
\end{tabular} & 0.113 & \begin{tabular}{|l|}
0.027 \\
$(0.163)$ \\
\end{tabular} & 0.137 & $\begin{array}{l}0.245 \\
(0.430)\end{array}$ & 0.178 & \begin{tabular}{|l|}
0.035 \\
$(0.185)$ \\
\end{tabular} & 0.192 \\
\hline Public services & \begin{tabular}{|l|}
0.061 \\
$(0.239)$
\end{tabular} & 0.102 & \begin{tabular}{|l|}
0.253 \\
$(0.435)$ \\
\end{tabular} & 0.136 & \begin{tabular}{|l|}
0.264 \\
$(0.441)$
\end{tabular} & 0.238 & \begin{tabular}{|l|}
0.466 \\
$(0.499)$ \\
\end{tabular} & 0.203 \\
\hline Other services & \begin{tabular}{|l|}
0.027 \\
$(0.163)$
\end{tabular} & 0.178 & \begin{tabular}{|l|}
0.017 \\
$(0.131)$
\end{tabular} & 0.145 & \begin{tabular}{|l|}
0.040 \\
$(0.197)$
\end{tabular} & 0.157 & \begin{tabular}{|l|}
0.035 \\
$(0.185)$ \\
\end{tabular} & 0.205 \\
\hline
\end{tabular}

*mean value 
Table 2. Reliability measure alpha Cronbach's of each dimension

\begin{tabular}{|c|c|c|c|c|}
\hline \multirow[t]{2}{*}{ Alpha Cronbach' } & \multicolumn{2}{|c|}{ Men } & \multicolumn{2}{|c|}{ Women } \\
\hline & $2006 / 07$ & $2009 / 10$ & $2006 / 07$ & $2009 / 10$ \\
\hline Intrinsic job quality & 0.748 & 0.807 & 0.770 & 0.814 \\
\hline Rewards & 0.687 & 0.581 & 0.660 & 0.580 \\
\hline Working time & 0.764 & 0.720 & 0.744 & 0.727 \\
\hline Insecurity ${ }^{a}$ & -- & -- & -- & -- \\
\hline Work environment & 0.792 & 0.794 & 0.797 & 0.789 \\
\hline Prospects & 0.759 & 0.677 & 0.708 & 0.620 \\
\hline
\end{tabular}

ansecurity reliability value omitted because its unidimensionality. 
Table 3. Standardized factor loadings and standard errors of the measurement model of each dimension of quality of work (Model 1) for the involuntary temporary employment by gender and period.

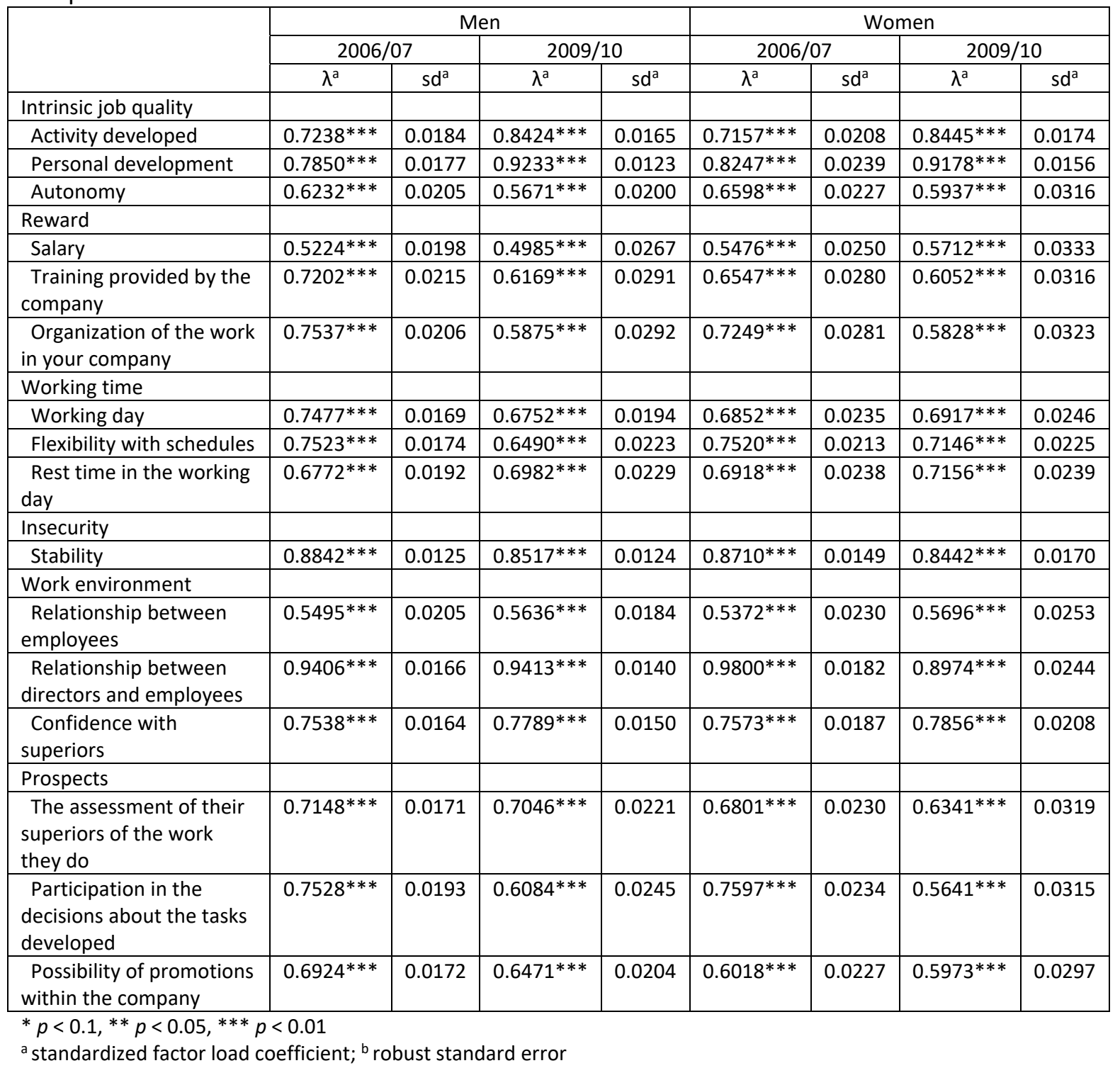

* factor fit not reported as is based in only one indicator 
Table 4. Standardized factor loadings and standard errors of the hierarchical measurement model (Model 2) for the involuntary temporary vs. permanent employment on the overall quality of work by gender and period.

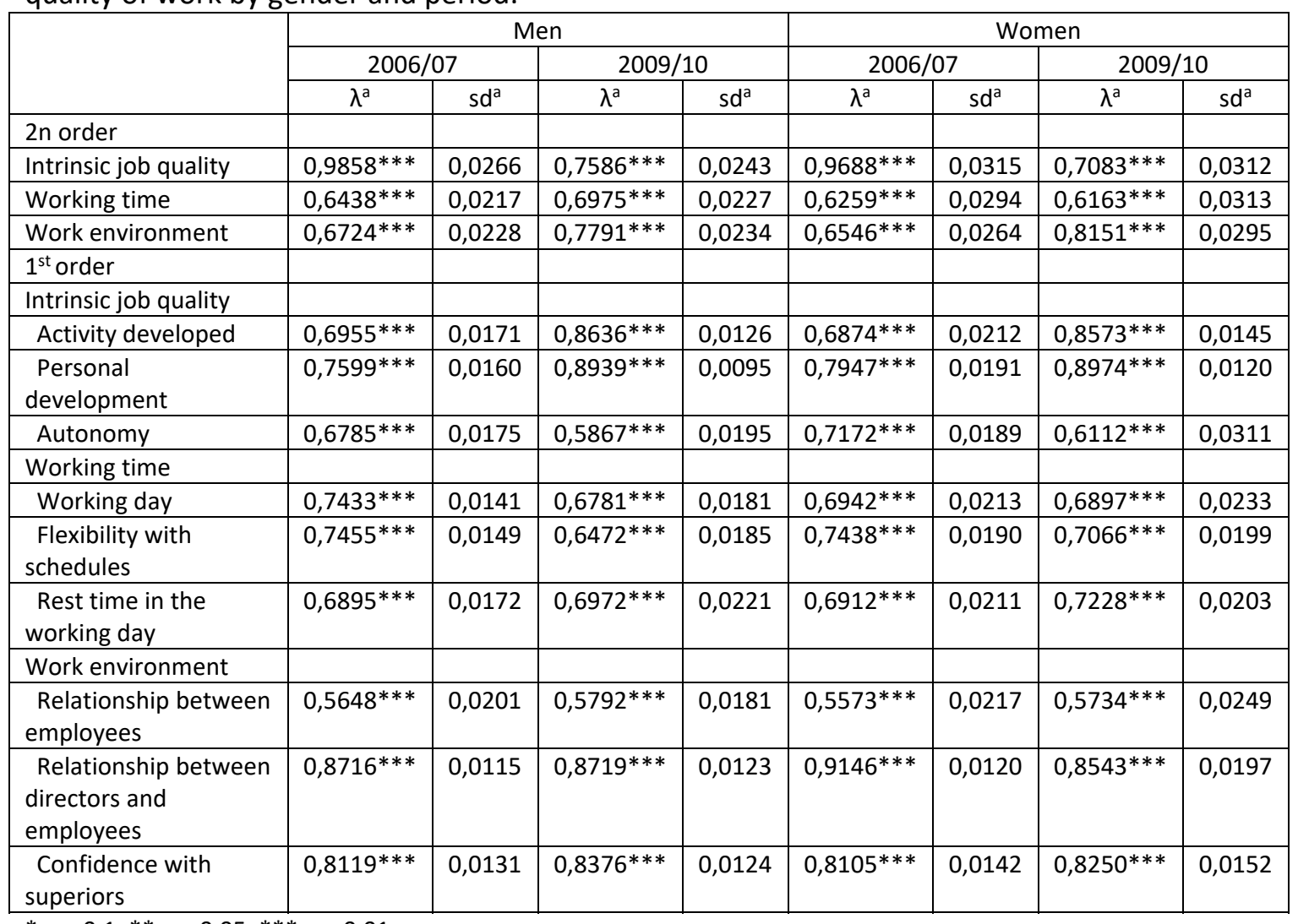

$* p<0.1, * * p<0.05, * * * p<0.01$

${ }^{a}$ standardized factor load coefficient; ${ }^{b}$ robust standard error 
Table 5. Association between the involuntary temporary vs. permanent employment and the overall and for each dimension of the quality of work (Model 1 \& Model 2 ) by gender and period.

\begin{tabular}{|c|c|c|c|c|c|c|c|c|}
\hline & \multicolumn{4}{|c|}{ Men } & \multicolumn{4}{|c|}{ Women } \\
\hline & \multicolumn{2}{|c|}{$\begin{array}{c}2006 / 07 \\
(N=4735)\end{array}$} & \multicolumn{2}{|c|}{$\begin{array}{c}2009 / 10 \\
(N=4864)\end{array}$} & \multicolumn{2}{|c|}{$\begin{array}{l}2006 / 07 \\
(N=2920)\end{array}$} & \multicolumn{2}{|c|}{$\begin{array}{l}2009 / 10 \\
(N=3072)\end{array}$} \\
\hline & beta $^{a}$ & $s d^{b}$ & beta $^{a}$ & $s d^{b}$ & beta $^{a}$ & $s d^{b}$ & beta $^{a}$ & $s d^{b}$ \\
\hline \multicolumn{9}{|l|}{ Unadjusted $^{\mathrm{c}}$} \\
\hline \multicolumn{9}{|l|}{ Model 2} \\
\hline Quality of work & -0.8369 & 0.9560 & -0.0287 & 0.0858 & -0.5817 & 0.4765 & $-0.3235 * * *$ & 0.0982 \\
\hline \multicolumn{9}{|l|}{ Model 1} \\
\hline Intrinsic job quality & $-0.222 * *$ & 0.0746 & -0.1621 & 0.0989 & $-0.2549 * *$ & 0.0927 & $-0.2846 * *$ & 0.1173 \\
\hline Reward & $-0.2667 * * *$ & 0.0710 & $-0.3635 * * *$ & 0.0808 & -0.1335 & 0.0943 & $-0.7093 * * *$ & 0.1397 \\
\hline Working time & -0.1312 & 0.0911 & -0.1047 & 0.0918 & 0.0645 & 0.0983 & $-0.4583 * * *$ & 0.1372 \\
\hline Insecurity & $-2.3578 * * *$ & 0.1342 & $-2.8558 * * *$ & 0.1723 & $-2.6306 * * *$ & 0.1661 & $-3.4310 * * *$ & 0.2059 \\
\hline Work environment & $0.0910 *$ & 0.0519 & $0.1173 * *$ & 0.0542 & 0.0236 & 0.0552 & $-0.2170 * * *$ & 0.0743 \\
\hline Prospects & $-0.3911 * * *$ & 0.1013 & $-0.4353 * * *$ & 0.0969 & $-0.4552 * * *$ & 0.1200 & $-0.6152 * * *$ & 0.1192 \\
\hline \multicolumn{9}{|l|}{ Adjusted $^{c}$} \\
\hline \multicolumn{9}{|l|}{ Model 2} \\
\hline Quality of work & -0.2851 & 0.1981 & 0.0857 & 0.0859 & 0.0596 & 0.2461 & $-0.2990 * *$ & 0.0942 \\
\hline \multicolumn{9}{|l|}{ Model 1} \\
\hline Intrinsic job quality & $-0.1613 * *$ & 0.0709 & -0.0376 & 0.0897 & -0.0719 & 0.0853 & $-0.2097 * *$ & 0.0921 \\
\hline Reward & $-0.2120 * *$ & 0.0721 & $-0.2332 * *$ & 0.0812 & 0.0539 & 0.0946 & $-0.6386 * * *$ & 0.1314 \\
\hline Working time & 0.0382 & 0.0943 & 0.0162 & 0.0901 & $0.1917^{*}$ & 0.1012 & $-0.3830 * * *$ & 0.1314 \\
\hline Insecurity & $-2.2004 * * *$ & 0.1318 & $-2.5818 * * *$ & 0.1763 & $-2.4197 * * *$ & 0.1531 & $-3.2654 * * *$ & 0.1933 \\
\hline Work environment & 0.0221 & 0.0569 & $0.1312 * *$ & 0.0532 & $0.1190 * *$ & 0.0574 & $-0.1649 * *$ & 0.0689 \\
\hline Prospects & $-0.3710 * * *$ & 0.1042 & $-0.2697 * *$ & 0.0955 & $-0.2201^{*}$ & 0.1153 & $-0.5186 * * *$ & 0.1125 \\
\hline
\end{tabular}

$* p<0.1, * * p<0.05, * * * p<0.01$

${ }^{a}$ standardized regressions coefficient; ${ }^{b}$ robust standard error

'unadjusted: raw regression coefficients; adjusted: adjusted regression coefficient by covariates: age, marital status, have children below 15 years, have disabled at household, education level, satisfaction with life, education level mismatch, occupation, size of the firm, economic activity, region. 